International Journal on Integrating Technology in Education (IJITE) Vol.7, No.1, March 2018

\title{
Design of an Anatomical Simulator for Medical Training. A 3D Printing Project Of Industrial Designers ANd Medical Students.
}

\author{
Juan Sebastián Avila Forero ${ }^{1}$, Manuel Martínez Torán² and Marco De Rossi \\ Estrada $^{2}$ \\ ${ }^{1}$ Creation and Communication Faculty, Universidad El Bosque, Colombia. \\ ${ }^{2}$ Drawing Departament, FabLab Valencia, Universitat Politècnica de València, Spain. \\ ${ }^{3}$ Design, manufacturing and management of industrial projects, $\mathrm{PhD}$ student at the \\ Universitat Politècnica de València, Spain.
}

\begin{abstract}
The Phantoscar project is a human body simulator recreated in a three-dimensional physical platform, with realistic position of organs and systems, obtained by means of $3 D$ printing, to perform simulations by catheterization or laparoscopy in its specific spatial location within the human body and thus to realize different types of customized surgical simulations.

It is the result of coordinated work between designers, engineers and health specialists, based on the use of additive manufacturing technologies, medical image segmentation and polygonal mesh editing (MESH), development of molds and reproductions with synthetic materials and similar properties to the tissues of the human body.
\end{abstract}

\section{KEYWORDS}

Anatomy, 3D printing, Digital, Sculpture, Education, Simulation.

\section{INTRODUCTION}

3D printing technologies have become an important tool for manufacturing on 21 st century, finding new applications in different areas of research, being the medical field one of the most striking in terms of application, with a wide diffusion in terms of scientific communication and mass media, which has opened a space for an economic exploitation in the market. [1.]

This article presents the workflow for the design and manufacture of organs and/or customized simulators using different technologies commonly used by design professionals and threedimensional modelling, in order to illustrate how the training phantom would work with different Configurations, demonstrating the efficiency of the applied techniques, the advantages and the potential of the phantom so that it can become a helpful program.

For several years, thanks to advances in medical imaging, the way doctors and surgeons can visualize and plan interventions has evolved, initially from two-dimensional resources like x-rays, then three-dimensional manipulating a virtual 3D model on a computer and currently materializing in three dimensions parts of the human body through 3D printing. This advancement in terms of surgery planning and human body understanding, has allowed to customize three-dimensional physical surgical guides, personalized organs of real patients for study and training simulators and surgical planning. [2.]

"You only have one opportunity to carve a graft obtained from a patient's rib, so you have to do it perfectly the first time, it takes years of practice to learn the technical skills to do it. This was a 
very realistic experience and what is great is that you can continue printing dozens of these models at the same time so you can practice again and again", says Dr Cher Zhao, University of Michigan Medical School resident. [3.]

Starting from the boom and advances in 3D printing it is now possible to customize, materialize and three-dimensionalize organs and internal systems to visualize and physically feel anatomical structures of patients before performing any intervention. [4.]

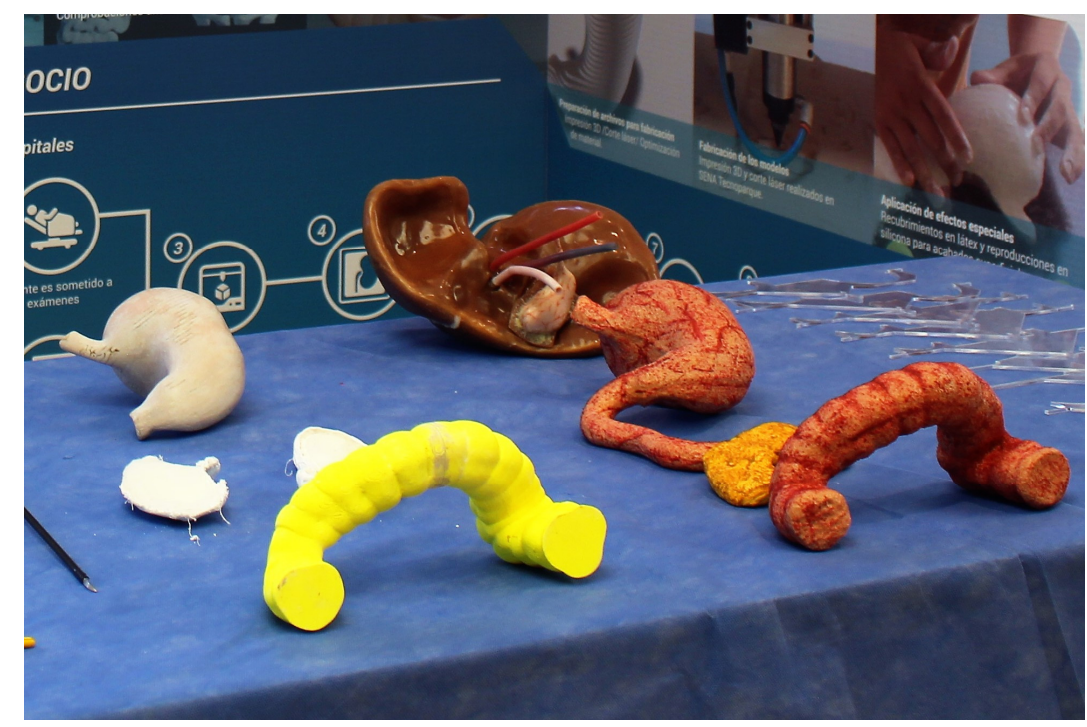

Figure 1. Simula Project. Organs made from 3D printing of models and molds, reproductions with silicones. Degree work. Student: I.D. Leonel Hernández. Director: Prof: Juan Avila

El Bosque University. 2016

Using materials and effects that simulate the context that can be found in a real patient and thus to prepare a better surgical intervention, contributing to patient and specialist safety, increasing the chances of success in an intervention. [5.]

On a relevant field, 3D manufacturing and printing methods have been evolving rapidly in the last 10 years, making the technology more accessible and with more applications in institutions and with the general public thanks to the Maker Movement [6.] [7.], nevertheless it is a field that continues developing and that is in a crucial point so that, large projects can be built with few resources to have endless possibilities of exploration. [8.]

This project plans to showcase a successful application of these technologies, as well as their viability and relevance in the field of medical training.

The research carried out is the result of a coordinated work between the "Universidad El Bosque de Bogotá", the "Hospital La Fe de Valencia" and the "Universidad Politécnica de Valencia" to manufacture a simulator for medical training to improve the skills of surgeons in the practice of a surgical intervention through catheterization technique and subsequently modified to increase its spectrum use with surgical laparoscopic procedures.

In this research - the development is done from the point of view of design and all factors related to doing and coordinated work with specialists in health areas, validating the Phantom manufacture [9.] and its materialization in teaching terms and clinical simulation. 
The cerebral aneurysm by catheterization operation was selected as a flag project, given its complexity to exemplify the possibilities of the PhantOscar simulator as a training tools.

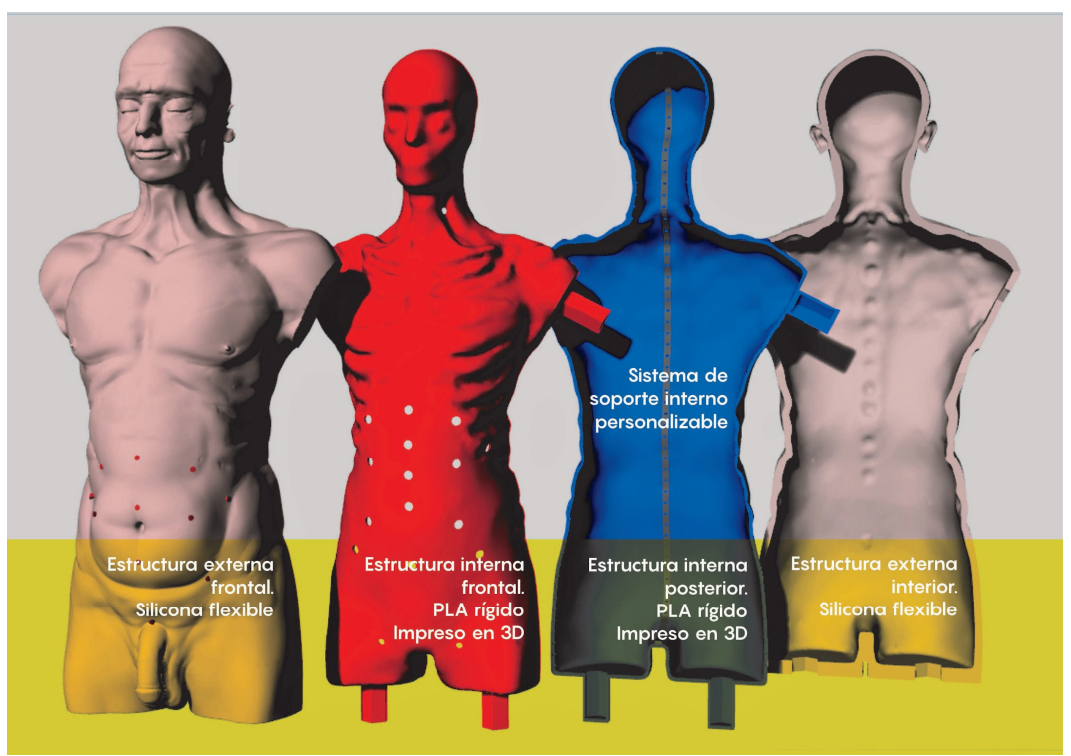

Figure 2. 3D model structures from PhantOscar Simulator.

El Bosque University. 2016.

The main objective of the simulator development, was to create a platform to spatially locate personalized organs or systems obtained from each patient at the approximate XYZ points within the human body at the surgery table, using as a model a man of approximately fifty years, so that medical surgeons approach the simulator with an adequate posture and thus develop confidence and muscular memory in simulation practices in a more realistic environment, contributing in some measure to the efforts that researchers from all over the world, who are performing customized models in planning and medical training from medical imaging and 3D printing technologies.

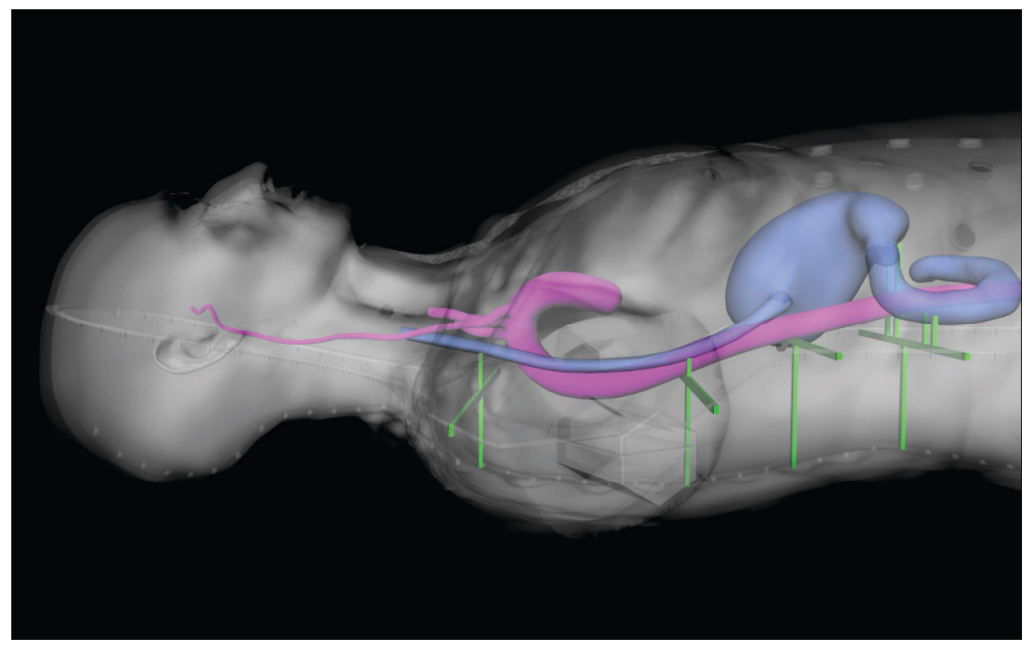

Figure 3. Customized internal organ positioning system. Phantoscar Project

On the other hand, currently on the market there is a wide range of simulators that fall short in the training of students in terms of emotional reality [10.], being models with a low human empathy, 
a low level of anatomical detail in relation to the morphology, textures and sensations of the real patients. "The great difficulty of medicine teaching lies in the fact that learning must not only be aimed at the acquisition of intellectual capacities or knowledge, but also to the development of psychomotor or practical skills and affective conditions or attitudes". [10.]

For the development of PhantOscar phantom, some techniques and specialized materials brought from the special effects industry were implemented.

This article is not intended to discuss the usefulness, techniques or any aspect referring to surgery as a medical procedure, it presents a development from the training point of view of the industrial designer office and the use of applied manufacturing technologies in the medical world.

\section{Materials AND MethodS}

Simulation phantoms are elements used to represent characteristics of the human organism, either as a training tool or only as a representation for educational and information purposes. [11.]

For the development of the PhantOscar phantom, different prototypes of virtual and physical approximation were made to validate the proposed design and thus offer greater realism and obtain better results in terms of appearance, using contributions and feedbacks in the creation process of the simulator of specialists in areas of health and medical training who will use it in the future for their practices, allowing an interdisciplinary co-creation process. [12.]

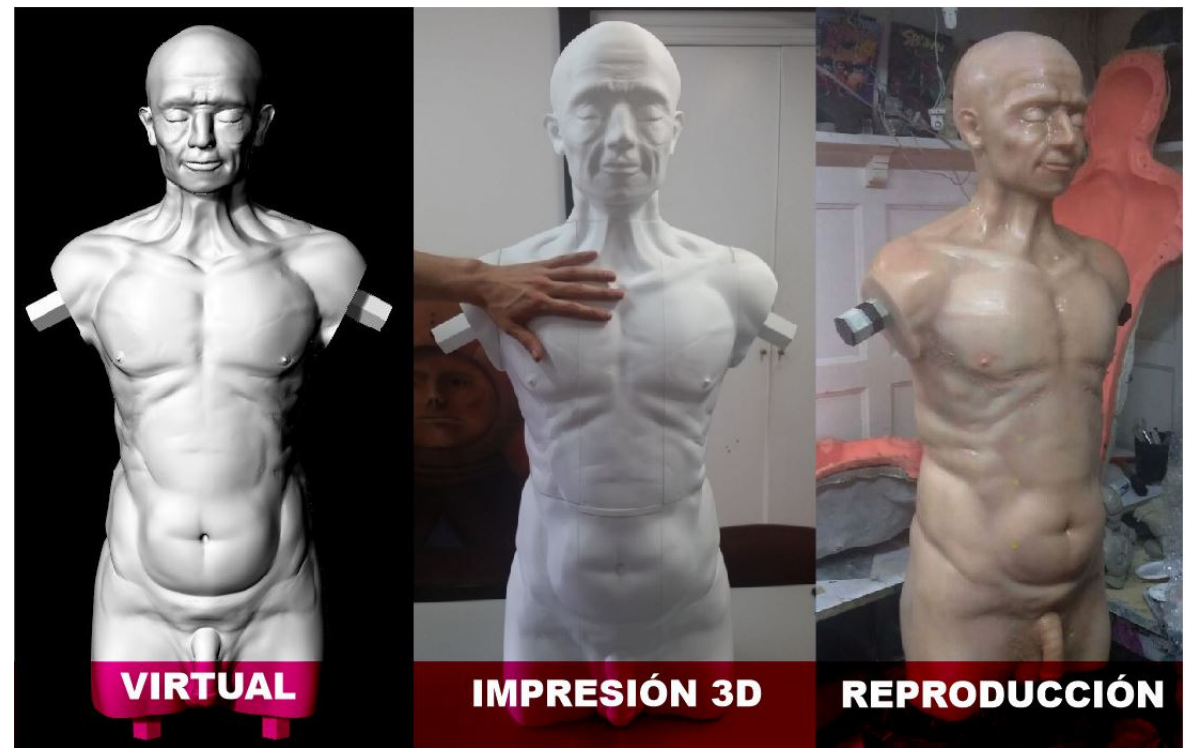

Figure 4. Left to right, Virtual model in Rhinoceros, 3D printed model in PLA, reproduction in silicone. Phantoscar Project. Prof. Juan Avila. El Bosque University. 2017

As a case study we selected the simulation of cerebral aneurysm surgeries by catheterization due to the high complexity of this type of operations and as a flag project in order to illustrate the procedure complexity that could be simulated on the PhantOscar physical platform, taking it more as a manufacturing challenge than by factors like economics, logistics and profitability in the first step of development.

The project was divided into two large segments to answer two specific interests, the first one, the problematic referred to phantoms realism of medical training where some problems were exposed regarding the approach, attitude and seriousness of the students about simulation practices, to understand the phantom more like a doll or an object and not as a potential patient. [10.] 
The clinical simulation and safety of the patient area at the Hospital Universitari i Politècnic La Fe suggested that the phantom could be made with materials that would resemble textures and sensations offered by human skin, and should have a physical appearance more like a person between 40 and 60 years of age (closer to the average age of patients of these kinds of interventions), noticing natural wrinkles, expressions and imperfections of a human being, in addition to work for various types of operations which should allow the customization and flexibility of the simulator according to the necessary conditions for each procedure.

At this point it is important to emphasize that there are many different procedures that have their special characteristics, and there is a large number of students and professionals in the health areas who must rotate in different training simulators, which makes the versatility of simulation and practice systems, a very important factor to take into account.

The second requirement was to be able to perform simulations with specific organs or systems and personalized for each patient, specifically for the development of training simulators for operations of high risk of cerebral aneurysms.

The technique used was the process of transformation of medical images, particularly.

DICOM (Digital Imaging and Communication in Medicine) [13.] Standard worldwide recognized for the exchange of medical tests, designed for handling, viewing, storing, printing and transmitting, in editable files. STL (Standard Triangle Language) o Mesh (Polygonal meshes) computer file formats of computer-aided design (CAD). [14.]

These editable files allow patients' organs to be edited in any way in a virtual environment to be printed in three dimensions, allowing doctors to have a visual and tactile feedback in order to evaluate possible complications, train muscle memory and perform an intervention and visualize the spatial relationships between the elements that will intervene in surgery. [15.]

These organs can be printed in three dimensions with different technologies that allow to simulate different necessary characteristics for the training or the medical education, rigid and flexible printing materials can be used over a wide range of physical properties. It is also possible to make reproductions using mixed techniques of manufacture that include the use of molds with special silicones, allowing organ replicas in different materials, thus emulating almost any anatomical structure of the human body. [16.]

3D printing describes the manufacturing process concerning the addition of material layer by layer to build a three-dimensional volume. It currently is divide into some categories depending on the type of technologies used.

There are variables such as the material and the technological process; FDM (Fused Deposition Modeling), SLS (selective laser sintering), SLA (Stereolithography), Polyjet (Injection of material drop by drop) among others, that allow to reproduce a wide range of materials with differentiated properties according to its specific application. [17.]

These 3D printing techniques still present some limitations in terms of long series reproductions and the availability of materials to represent some necessary properties to simulate anatomical structures. These problems were solved using traditional reproduction techniques through molds, thus allowing to cast specific materials such as silicones with a wide range of properties, that emulate some sensorial characteristics of the layers of the skin, muscle, fat and bone of the human body, additionally makeup techniques and painting were taken that allowed to recreate a more realistic anatomical system. [18.]

It should be noted that these techniques, such as 3D printing or the segmentation of medical scanners in editable files have a very deep and specific technical aspect, where the technology 
selection, printing or conversion parameters and the specific material to be used make it a specialized process.

Nevertheless, these developments are still in constant evolution allowing enthusiasts to contribute with specific research and opening a wide field of applied research all over the world.

\section{Clinic Simulation:}

Clinical simulation is a teaching methodology that provides a fast and effective learning curve, using physical or digital models, to increase patient treatment security and attend to the ethical imperative of non-human experimentation, supposing a significant reduction of the costs added to the health system due to the problems that can be derived from the inexperience of a doctor. [19.]

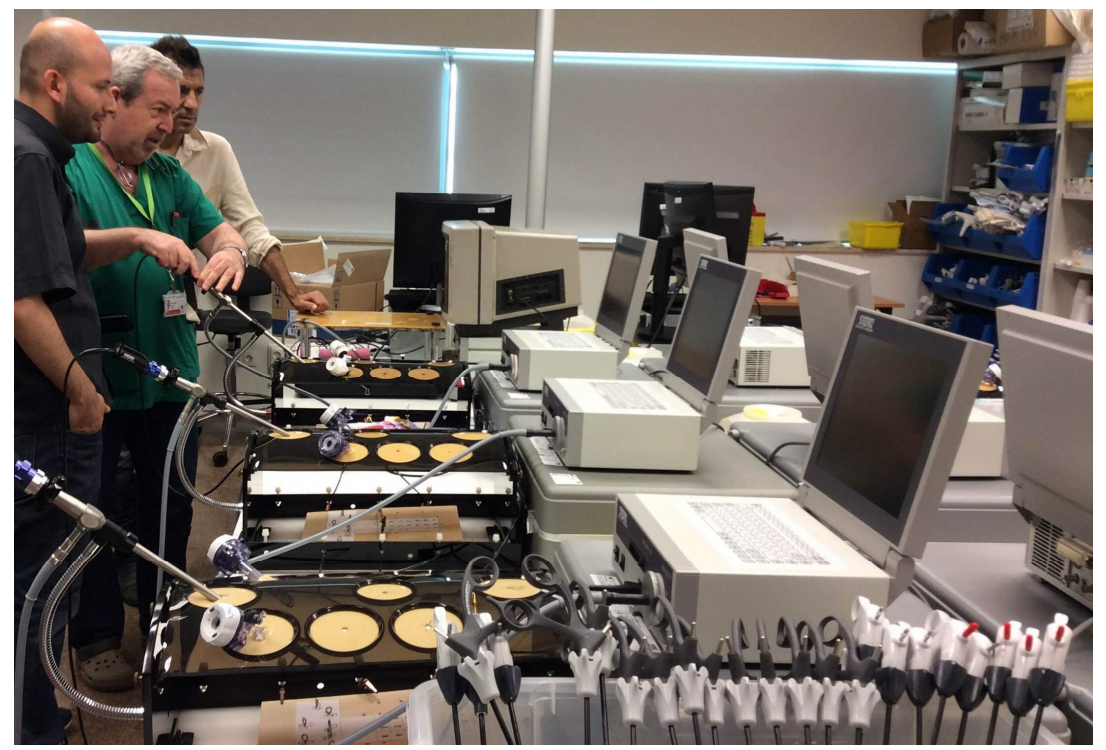

Figure 5. Field work, Clinical simulation laboratory and patient safety, Hospital Clinical Simulation and Patient Safety Hospital Universitari I Politècnic La Fe de Valencia.

. Prof. Juan Avila, Dr. Jose Dolz

The importance of the research processes - creation processes for the development of medical material for training and preparation of medical surgeons, represents an advance for medicine and the safety of the patient, allowing training doctors to make an anatomical approach to standardized characteristics of the human body and the specificities of each patient that can be personalized and thus to know and understand the variables that can arise in high risk surgeries in a real context, simulated and controlled. Tools and scenarios are provided for training where it can fail without consequences for patients.

\section{From The Medical Image To The Simulator.}

The transformation process of a medical image to a three-dimensional medical object is a technique that takes a considerable mixture of expertise, from radiology to 3D modeling and digital manufacturing to be done correctly, but for a general reproduction for training, it can be done with some open source and free software and some practice.

For this simulator, computed tomography angiography (CTA) was selected, being one of the techniques that best helps to define the morphologies dimensions of an aneurysm. [20.] 
CTA is based on volumetric scanning of the brain after an intravenous injection of a contrast medium. The quality of the images has been developed by multi-slice technology and the development of post processed hardware and software. [21.]

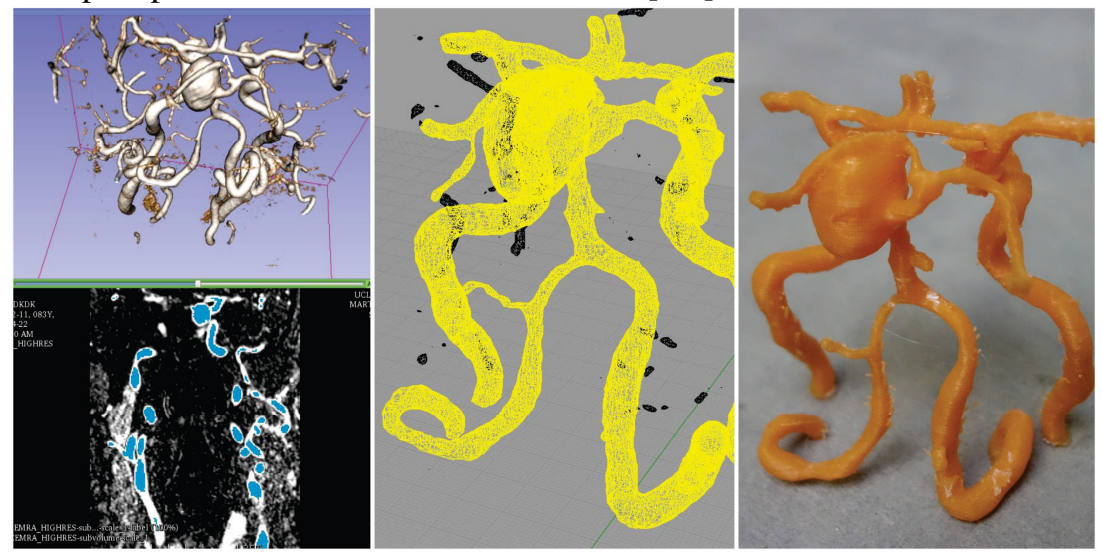

Figure 6. Printed Model Brain Aneurysm, Slicer3D Software, Fab Lab VLC 2015.

Usually, surgeons establish the requirements for computed tomography, while 3D reconstruction of anatomical areas of interest is done by an engineer or designer with specialized software: Mimics, 3D-Doctor, Osirix, InVesalius, etc. During the pre-surgical planning stage, the surgeon and the designer / engineer must collaborate to define and then transfer the virtual model of the anatomical models. [20.]

Led by the Maker revolution and the concept of open software development, free resources and 3D printing have seen widespread adoption as a tool for low cost prototyping. Development and innovative products are now possible without having to rely on expensive software or services, allowing researchers who wish to find a niche for an application.

The constant growth of the number of professionals in digital design, engineering or artists capable of interpreting and creating complex morphologies such as those of the human body in three-dimensional digital volumes with an astounding level of detail has been one of the drivers along with the technological revolution of the "do it yourself" [22.]

\section{Study Case: Operation Of Cerebral Aneurisms By Cathederism.}

An aneurysm refers to a weak area in the wall of a blood vessel that causes a swelling with the possibility of a rupture resulting in bleeding or hemorrhage within the human body, being cerebral aneurisms the most dangerous given its condition within the skull and its damage to the brain. [21.]

There are two common methods used to treat an aneurysm: clipping, that is done during an open craniotomy, placing a metal clamp on the aneurysm base to prevent it from rupturing, and endovascular repair by catheterization, most cases performed with metal spirals or the use of metal mesh tubes known as stents, which travel within the arteries and veins to create an internal bridge or fill the space within the aneurysm which minimizes internal pressure and prevents a rupture, being this one of the most used techniques thanks to the percentage of success and less trauma for the patient. "Dr. Adnan Siddiqui, a neurosurgeon at Kaleida Health and the Chief of Medical Service at the Jacobs Institute, described that he was "able to test these innovative devices and perform dry tests before making actual cases to ensure we have the right size, get the right tools, make sure we have all the additional information to make these procedures safer and better and more effective for our patients." [23.] 
International Journal on Integrating Technology in Education (IJITE) Vol.7, No.1, March 2018

Factors such as blood pressure, vessel dilation and delicate and differentiated structures between patients, make the catheterization technique operations an intervention that must be practiced in real patients, making it very difficult to perform simulations and surgical practices with human specimens in an amphitheater.

For surgeons to acquire the necessary skills to guide the catheter (wire that is introduced through the arteries) through a small incision and then to the blood vessel in the brain where the aneurysm is located, requires many hours of practice and sensitization in the management of the catheter. [24.]

Brain aneurysm surgeries are usually interventions that must be performed immediately when a patient presents with a clinical episode, which in many cases does not give time to plan the intervention.

Specifically, in the development of simulators for catheterization cerebral aneurysm surgery, different simulators have been presented by different 3D printing companies such as Stratasys [23.], being one of the flags project of these companies to illustrate the benefits of their machines and the latest technology available for developments in the medical field, showing the power of their printers to create hollow structures with high level of detail, but with rigid structures and isolated from the actual system that a surgeon could find on an operating table, useful to visualize morphology in a physical model but with enough limitations to perform a practical simulation.

These practical simulations are a necessary training not only for students of surgery but also for the same expert surgeons, since they can provide the possibility of performing a preoperative practice in which variables are determined and uncertainty is reduced in relation to the procedure, increasing the percentages of success in operations. [18.]

The training and planning of catheter interventions just before the actual procedure benefits the patient in relation to a reduced number of catheter repositioning, reduces the time spent in a real case and consequently decreases the cost of treatment. [25.]

\section{Phantoscar Simulator Development And Positioning System.}

For the development of the Phantoscar simulator, standard human body files were obtained from the free three-dimensional anatomy library in polygonal mesh language "BodyParts3D Anatomography" of the Japanese project lifesciencedb, [26.], which were edited with techniques of image processing and digital sculpture in specialized programs such as Rhinoceros, MudBox, 3DStudio Max, MeshMixer y Zbrush.

The edition of these base models were carried out according to the recommendations of Dr. José Francisco Dolz, director of the "clinical simulation and patient safety area" of the Hospital Universitari i Politècnic La Fe, who, given his experience, proposed formal and sensorial changes in the design of the phantom simulations, trying to improve aspects of the simulator's perception by the trainees to confront the training and teaching processes with more respect, understanding that the human body presents imperfections, tactile sensations of temperature, texture, color in patients of advanced age and with some medical complication, wanting to contribute from another point of view to the development of future simulators so that the Phantom will not be made of rubber in which some very important but incomplete aspects are simulated in its symbolic approach towards the interventions and other human factors that intervene in a clinical simulation from the formative point of view.

Historically, a surgeon's skills have been acquired in living patients, anesthetized animals or human cadavers, but teachers, surgeons and specialists agree that surgical simulation is increasingly recognized as a vital educational tool for a professional's development [24].

To this end, different rendering techniques developed by the special effects industry for entertainment were studied and implemented, starting from the digital sculpture to develop and 
parameterize productive aspects by $3 \mathrm{D}$ printing and to be able to have a virtual reference of spatial positioning in a three-dimensional virtual environment to locate the different systems and internal organs that conform the human body.

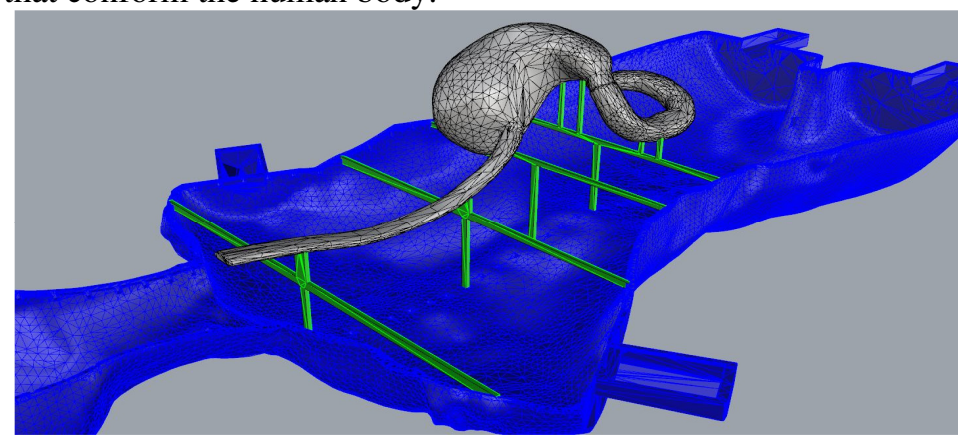

Figure 7. System Positioning System, Rhinoceros Software, PhantOscar Project. Prof: Juan Avila. 2016

As an aspect to be highlighted in the development of the phantom, 3D printing was used as a tool to materialize the necessary models for the fabrication of the first prototype, which served to evaluate and exemplify the relevance of these manufacturing techniques in the development of medical simulators for teaching environments, a Delta Wasp 2040 printer was used in FDM technology because it is one of the printers with height capacity of 40 centimeters, according to the needs of the project and the anatomy of the human torso.

The internal system of the phantom allows to locate the personalized organs or systems of the actual patients in their approximate spatial location within the simulator, through a laminated system coded and customized according to the specific needs of each operation, that allows to support the organs within PhantOscar helps emulate the position and posture of the surgeons at the moment of making a simulation before a surgical intervention by laparoscopy or catheterization in a real patient, always if the operation is provided in a horizontal position and face up on the operation table.

This process is carried out by specialized software of three-dimensional modeling where the 3D modeling file of the organ obtained through a medical scanner in DICOM format is imported and converted into a $3 \mathrm{D}$ digital format within a three-dimensional coordinate system where the approximate point of the organ is positioned manually in its natural location according to a virtual guide where all the main organs of the human body are found.

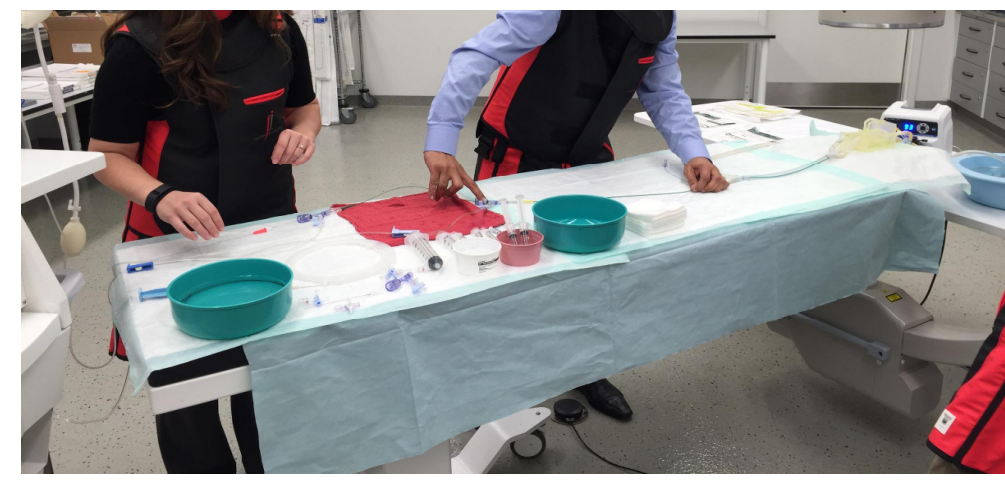

Figure 8. Doctor (right) and his lab assistant (left) practice placing catheters and medical devices inside the 3-D model of a brain aneurysm. Credit Avery Schneider / WBFO News 
International Journal on Integrating Technology in Education (IJITE) Vol.7, No.1, March 2018

\section{CONCLUSION}

The PhantOscar simulator was realized with modeling techniques and three-dimensional digital sculpture, 3D printing and the work with human body molds, aiming to represent a senior man and with sedation gesture to become a reference for future of medical simulators developments.

Among the main project contributions is the anchoring system that allows to personalize the location of internal organs or systems, to place them in their correct position according to the patient to be treated, allowing the surgeon to be positioned in a realistic way while he is performing the simulation of the operation within the phantom.

This simple but fundamental simulation contribution allows the surgeon to acquire skeletal muscle memory skills according to the procedure to be performed, in an approximate position in which he will be on the operating table and with a symbolic reference that helps training students to develop a more coherent approach.

The project has been supervised by Dr. Jose Dolz, director of the clinical simulation and patient safety area of the Hospital Universitari i Politècnic La Fe, Dr. Armando López y Dr. Dr. Julio César Bermúdez from Universidad El Bosque of Bogotá, Director and Coordinator of the Center for Experimental Surgery, who have opined that this type of technology and advances in simulation help directly the development of training doctor's skills. Activities of approach and recognition of the needs of the clinical simulation laboratories have been carried out, confirming the potential and usefulness of PhantOscar phantom within the clinical practice processes and as training tool.

The potential process does not stop in the practice of real patients, it is anticipated that the most common use is in the physicians training at all stages of their education, using generic models of the human anatomy, also envisioning a potential in the testing of device use and technological prototypes in healthcare fields. [23.].

It is intended at a later stage to further validate the results, with a relevant statistical sample, to evaluate some clinical cases that are relevant to showcase the effectiveness of the simulator in terms of realism and benefits to the prognosis.

\section{REFERENCES}

[1.] Azcaray Fernandez, Joseba K. Product Design \& 3D Printing: Integrating New Technologies into The Curriculam - Case Study. International Journal on Integrating Technology in Education (IJITE) Vol.6, No.4, December 2017

[2.] Hongtao, Z., Xuemin, D., Huimin, Y., Zeyang, W., Lijuan, Z., Jinxin, Z., . . . Juan, W. (2016). Dosimetry study of three-dimensional print template-guided precision 125I seed implantation. Journal of Cancer Research and Therapeutics, 12(7), 159-165. doi:10.4103/0973-1482.200607

[3.] 3D printing helps surgeons sharpen their craft. (2017). Surgical Products, Retrieved from http://ezproxy.unbosque.edu.co:2048/login?url=http://search.proquest.com/docview/1889204044?acc ountid=41311

[4.] Park, J. H., Lee, Y., Shon, O., Shon, H. C., \& Kim, J. W. (2016). Surgical tips of intramedullary nailing in severely bowed femurs in atypical femur fractures: Simulation with 3D printed model. Injury, 47(6), 1318-1324. doi:10.1016/j.injury.2016.02.026

[5.] Trigo, G., Paganini, C. I., Saiz, G. F., \& Vilachá, M. I. (2016). Precisión en la planificación quirúrgica 3D en un paciente con síndrome de goldenhar. Revista Española De Cirugía Oral y Maxilofacial, 38(2), 91-95. doi:10.1016/j.maxilo.2014.07.005

[6.] Martínez Torán, M. (2016). ¿Por qué tienen tanta aceptación los espacios maker entre los jóvenes? Cuadernos de Investigación en Juventud, ISSN 2530-0091. N $N^{\text {o }} 1$ Julio 2016. e003. doi: 10.22400/cij.1.e003. 
International Journal on Integrating Technology in Education (IJITE) Vol.7, No.1, March 2018

[7.] Ruiz Martín, José Manuel (2015). El crecimiento de los open sources de fabricación digital y su implementación en el media lab. de la high-tech al do it yourself. Comhumanitas, 6(1), 67-81.

[8.] Arias, V., Contreras-Velásquez, J., Chacón, J., Vera, M., Huerfano, Y., Graterol-Rivas, M., . . . Bermúdez, V. (2015). Impresión 3D de estructuras cardiacas: Caso de innovación frugal en sector salud/3D printing of cardiac structures: A case of frugal innovation in the health sector. Revista Latinoamericana De Hipertension, 10(4), 91.

[9.] CUN. Clínica Universidad de Navarra. Diccionario médico. Recuperado el 11 de Julio de 2016, del sitio web de la clínica de la Universidad de Navarra: http://www.cun.es/diccionariomedico/terminos/fantoma

[10.] Solares, G., M. González, A., Escalante, C., \& Delgado, T. (2004). Simuladores en la enseñanza médica en el pregrado, ¿novedad o necesidad? Medicina Clínica, 122(20), 798-799. doi:10.1016/S0025-7753(04)74391-2

[11.] Rodríguez-Díez, M. C., Díez-Goñi, N., Beunza-Nuin, J. J., Auba-Guedea, M., Olartecoechea-Linaje, B., Ruiz-Zambrana, Á., \& Alcázar-Zambrano, J. L. (2013). Confianza de los estudiantes de medicina en el aprendizaje de la exploración obstétrica con simuladores. Anales Del Sistema Sanitario De Navarra, 36(2), 275-280. doi:10.4321/s1137-66272013000200010

[12.] Colleen Marzilli, Julie Delello, Shelly Marmion, Rochell McWhorter, Paul Roberts and T. Scott Marzilli. Faculty Attitudes Towards Integrating Technology and Innovation. International Journal on Integrating Technology in Education (IJITE) Vol.3, No.1, March 2014

[13.] David A. Zopf, Anna G. Mitsak, Colleen L. Flanagan, Matthew Wheeler, Glenn E. Green, Scott J. Hollister. Computer Aided-Designed, 3-Dimensionally Printed Porous Tissue Bioscaffolds for Craniofacial Soft Tissue Reconstruction. Otolaryngology-Head and Neck Surgery, 2015; 152 (1): 57 DOI: $10.1177 / 0194599814552065$

[14.] Huotilainen, E., Jaanimets, R., Valášek, J., Marcián, P., Salmi, M., Tuomi, J., . . . Wolff, J. (2014). Inaccuracies in additive manufactured medical skull models caused by the DICOM to STL conversion process. Journal of Cranio-Maxillo-Facial Surgery : Official Publication of the European Association for Cranio-Maxillo-Facial Surgery, 42(5), e259. doi:10.1016/j.jcms.2013.10.001

[15.] Itagaki, M. W. (2015). Using 3D printed models for planning and guidance during endovascular intervention: A technical advance. Diagnostic and Interventional Radiology, 21(4), 338-341. doi:10.5152/dir.2015.14469

[16.] Kilic, D., Ustbas, B., Budak, E. P., Eyisoylu, H., Yilmaz, C., Eldem, B., \& Akbulut, O. (2016). Silicone-based composites as surgical breast models for oncoplasty training. Procedia Engineering, 159, 104-107. doi:10.1016/j.proeng.2016.08.131

[17.] Berchon, M., \& Luyt, B. (2016). La impresión 3D: Guía definitiva para makers, diseñadores, estudiantes, profesionales, artistas y manitas en general. Barcelona: Editorial Gustavo Gili.

[18.] Reid-Searl, K., Happell, B., Vieth, L., \& Eaton, A. (2012). High fidelity patient silicone simulation: A qualitative evaluation of nursing students' experiences. Collegian (Royal College of Nursing, Australia), 19(2), 77.

[19.] Amaya Afanador, A. (2010). Simulacion clinica: "aproximacion pedagogica de la simulacion clinica". Revista Universitas Medica, 51(2), 204.

[20.] Popescu, D., Laptoiu, D., Hadar, A., Ilie, C., \& Pârvu, C. (2015). workflow for additive manufacturing of an individualized surgical template. Proceedings in Manufacturing Systems, 10(3), 131.

[21.] Pardo-Pumar, M. I. (2009). Tratamiento endovascular de los aneurismas cerebrales mediante la utilización de coils largables. Santiago de Chile: Universidad de Santiago de Compostela.

[22.] Collective, T. T. (2007;2015;). Do it yourself: A handbook for changing our world. GB: Pluto Press.

[23.] Davis, H. (2016, ). Jacobs, stratasys merge 3D printing, medical research. TCA Regional News 
International Journal on Integrating Technology in Education (IJITE) Vol.7, No.1, March 2018

[24.] Francisco Álvarez, G. (2011). Accesos venosos centrales guiados por ultrasonido: ¿existe evidencia suficiente para justificar su uso de rutina? Revista Médica Clínica Las Condes, 22(3), 361-368. doi:10.1016/S0716-8640(11)70436-9

[25.] Mastmeyer, A., Fortmeier, D., \& Handels, H. (2016). Efficient patient modeling for visuo-haptic VR simulation using a generic patient atlas. Computer Methods and Programs in Biomedicine, 132, 161175. doi:10.1016/j.cmpb.2016.04.017

[26.] Mitsuhashi, N., Fujieda, K., Tamura, T., Kawamoto, S., Takagi, T., \& Okubo, K. (2009). BodyParts3D: 3D structure database for anatomical concepts. Nucleic Acids Research, 37(suppl_1), D782-D785. doi:10.1093/nar/gkn613

\section{AUTHORS:}

Juan Sebastian Avila Forero M.Sc, is a PhD student of design, manufacturing and management of industrial projects from U.Politécnica de Valencia - Spain. He received a bachelor's degree in industrial design from U. Nacional de Colombia and a Master's degree in product design from Politécnico Di Milano - Italy. His current field placement is with U. El Bosque - Colombia where he works as a Professor. He is interested in research of emergent technologies applied to product development for teaching, training and simulation in medical fields.

Manuel Martínez Torán PhD is a professor and design researcher at UPV and Director of FabLab Valencia. He has participated in two European and 25 R\&D design project as principal researcher (PI). He has published five books, twelve book chapters, fourteen contributions at conferences and has four recognized patents. He has been visiting lecture in Argentina, Mexico, Chile and Colombia. He has seven doctoral thesis read and one live stage of recognized research from Spanish Ministry of Education

Marco De Rossi Estrada M.Sc, is a PhD candidate of design, manufacturing and management of industrial projects from U. Politécnica de Valencia - Spain. He received a bachelor's degree in industrial design from U. Pontificia Bolivariana of Medellín - Colombia and a Master's degree in product design from Politécnico Di Milano - Italy. Curious about everything, with a big passion for new technologies. He had the opportunity to live, work and study in many countries, something that has given him an amazing view of the world. He has been an entrepreneur since very young, and hopes to start a new company once he completes his Doctorate studies.
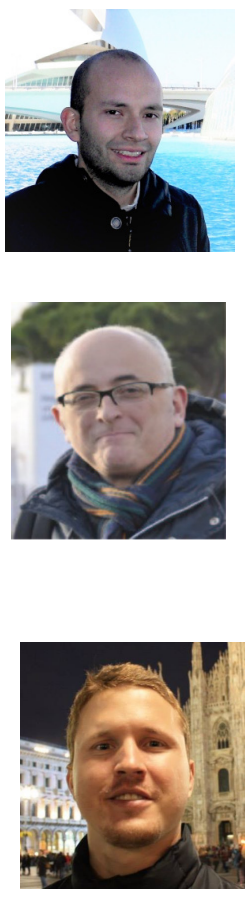